\title{
ChaLlenges in ENGineERING EdUCATiON of Cognitive Dynamic Systems
}

\author{
Witold Kinsner ${ }^{1}$, Simon Haykin², Yingxu Wang ${ }^{3}$, Witold Pedrycz ${ }^{4}$, Ivo Bukovsky, \\ Bernard Widrow ${ }^{6}$, Andrzej Skowron ${ }^{7}$, Piotr Wasilewski ${ }^{7}$, and Menahem Friedman ${ }^{8}$ \\ ${ }^{1}$ Department of Electrical and Computer Engineering, University of Manitoba, Winnipeg, MB, Canada R3T 5V6 \\ ${ }^{2}$ Department of Electrical and Computer Engineering, McMaster University, Hamilton, ON, Canada \\ ${ }^{3}$ Department of Electrical and Computer Engineering, University of Calgary, Calgary, AB, Canada T2N 1N4 \\ ${ }^{4}$ Department of Electrical and Computer Engineering, University of Alberta, Edmonton, AB, Canada \\ ${ }^{5}$ Division of Automatic Control and Engineering Informatics, Czech Technical University, Praque, Czech Republic \\ ${ }^{6}$ Department of Electrical Engineering, Stanford University, Palo Alto, CA, USA \\ ${ }^{7}$ Institute of Mathematics, Warsaw University, Warsaw, Poland \\ ${ }^{8}$ Departments of Physics and Systems Science Engineering, Ben Gurion University, Negev, Israel \\ w.kinsner@ieee.org
}

\begin{abstract}
Diverse attempts are being made to develop new computers, machines and systems that could act not only autonomously, but also in an increasingly intelligent, perceptual and cognitive manner. This paper discusses some of the educational challenges stemming from this emerging modelling and design paradigm, including teaching appropriate subjects to undergraduate and graduate students in university engineering programs.
\end{abstract}

Keywords: Design paradigms, adaptive systems, intelligent systems, cognitive systems; cognitive dynamic systems, cognitive engineering, cognitive informatics; education.

\section{INTRODUCTION}

\subsection{Motivation}

Numerous attempts are being made to develop new computers, machines and systems that could act not only autonomously, but also in an increasingly intelligent, perceptual and cognitive manner (e.g., [Ande05], [FrKa99], [Haik03], [Hayk12], [Kins06], [Mann02], [Pedr01], [SkWa10], [Wang02], [Wang06], [WaKZ09], [WaZK10], [Ward02], [Widr10]). Such cognitive entities ought to be aware of their environments that include not only other machines and systems, but also human beings. Such machines ought to understand the meaning of information in more human-like ways by grounding knowledge in the physical world (often stochastic, imprecise, fuzzy, ambiguous, uncertain, incompletely specified) and in the machines' own goals. Such entities often exhibit emergent behaviour. The motivation for developing such machines range from self-evident practical reasons such as the expense of system maintenance [Kins06] to wearable computing in health care [Mann02], and gaining a better understanding of the cognitive capabilities of the human brain [Ande05], [Widr10].

\subsection{Paradigm Shifts in Technology and Computing}

Computer science and computer engineering have contributed to many shifts in technological and computing paradigms. For example, we have seen shifts (i) from large batch computers to personal and embedded real-time computers, (ii) from control-driven microprocessors to data- and demand-driven processors, (iii) from uniprocessors to multiple-processors (loosely coupled) and multiprocessors (tightly coupled), (iv) from fixed-configuration processors to reconfigurable computing engines such as the field-programmable gate arrays, (v) from data-path processors to structural processors (e.g., neural networks [Bish95]), quantum processors [NiCh00] and biomolecular processors [SARC03], (vi) from silicon-based processors to biochips [RuBT05], (vii) from vacuum tubes to transistors to microelectronics to nanotechnology, (viii) from large passive sensors to very small smart active sensors [Solo99], (ix) from local computing to distributed computing and network-wide computing, (x) from traditional videoconferencing to telepresence (e.g., WearTel and EyeTap [Mann02]), (xi) from machines that require attention (like a palmtop or a wristwatch computer) to those that have a constant online 
connectivity that drops below the conscious level of awareness of users (like autonomic computers [GaCo03], [IBM06], and eyeglass-based systems [Mann02], [HaKo01]), (xii) from crisp-logic-based computers to fuzzy or neurofuzzy computers [PeGo98], as well as (xiii) from control-driven (imperative) systems to cognitive systems.

Various examples of this evolution are evaluated, including the shift from control-driven (imperative) systems to cognitive systems such as cognitive radio [Hayk05a] [Hayk05b], cognitive radar [Hayk06], active audition [HaCh05], cognitive networks [HoBF 12], [HoBh10], [HNZH09], cognitive DNA analysis [KiZh10], cognitive control [HFSX12], and cognitive robots [Wang10a], [Wang10b].

These remarkable shifts have been often necessitated by the system complexity which now exceeds our ability to maintain them [GaCo03]. Another reason for the shifts has been the need to improve utilization of resources such as frequency spectrum and power. The changes are being facilitated by new developments in technology, intelligent signal processing, and machine learning [HPSM06] and treatment of uncertainty [Kins].

Mischa Schwartz [Schw12] suggests a forthcoming evolution of a "wireless society" in which people communicate with other people, as well as with databases and machines over heterogeneous mobile networks through smartphones or tablets or by wireless laptops, without "seeing" the backbone optical (wired) network that carries information rapidly, timely, and accurately. Such a society ought to be based on cognitive radio (wireless) networks.

\subsection{Some Challenges}

To achieve such an ambitious goal requires solutions to many modelling and design problems, ranging from human perception, attention, concept creation, cognition, consciousness [Haik03], [Haik04], [Haik07] executive processes guided by emotions and value, and symbiotic conversational human-machine interactions. Cognitive informatics [Wang06], [WaKZ09], [WaDK10] has evolved to tackle at least some of those problems.

The evolution of engineering design from imperative systems to cognitive systems, together with the corresponding design challenges is discussed by Kinsner (e.g., [Kins06], [Kins09]).

The evolution of the wireless society and the corresponding cognitive radio networks (CRNs) demands their robustness and security. There are many security challenges in CRNs, both infrastructure-based and infrastructure-less. Possible short-term and longterm solutions to those challenges are being proposed

CEEA Conf. 2012; Paper 119

Winnipeg, MB; June 17-20, 2012 (e.g., [ATVY12]). Such solutions could be termed cognitive security [Kins12].

Based on the above examples from current research, including cognitive radio, cognitive radar, cognitive control, cognitive networks, and other cognitive dynamic systems [Hayk12], this paper discusses some of the educational challenges stemming from this emerging modelling and design paradigm, including teaching appropriate subjects to undergraduate and graduate students in university engineering programs.

The next section provides a few definitions and models of consciousness, and serves as a preamble for the scope of teaching dynamic systems.

\section{WHAT ARE COGNITIVE SYSTEMS?}

\subsection{What is Cognition?}

Since the 1950s, philosophers, mathematicians, physicists, cognitive scientists, neuroscientists, computer scientists, and computer engineers have debated the question of what could constitute digital sentience (i.e., the ability to feel or perceive in the absence of thought and inner speech), as well as machine consciousness or artificial consciousness (e.g., [Neum58], [Sear80], [Mins86], [RuMc86], [Cott88], [Posn89], [Kliv89], [Penr89], [Kurz90], [Denn91], [Sear92], [Penr94]). Consequently, many approaches have been developed for modelling consciousness, including biological, neurological, and engineering (applied and practical). The approach to cognition taken in this paper is mostly engineering in which the behaviour of a system can be observed, measured, characterized, modelled and implemented as an artefact, such as a cognitive robot (either isolated or societal) to improve its interaction with people, or a cognitive radio to improve the utilization of a precious resource, i.e., the frequency spectrum. In general, the intent of such cognitive systems is to improve their performance, to reduce waste in resource utilization, and to provide a test-bed for learning about cognition and cognitive processes. If an approach is purely reductionist, it may not be capable of describing the complexities of cognition. Since our engineering approach considers not only the individual components of a system, but also their interactions, it may be capable of describing the dynamics of cognitive processes. Although engineering approaches have serious limitations (e.g., [Pars05], [Cha197]), they are intended to produce a range of specific practical outcomes.

According to the Oxford Dictionary, cognition is "knowing, perceiving, or conceiving as an act." The Encyclopedia of Computer Science [RaRH03] provides a computational point of view of cognition consisting of the following three attributes: (i) cognition can be described by mental states and processes (MSPs) 
intervening between input stimuli and output responses, (ii) the MSPs can be described by algorithms, and (iii) the MSPs should lend themselves to scientific investigations.

Another view of cognition is suggested by Pfeifer and Scheier [PfSc99; pp. 5-6] as an interdisciplinary study of the general principles of intelligence through a synthetic methodology termed learning by understanding.

Cognition also includes language and communications, as studied in different forms (e.g., ([FiFi87], p.81), [RoPe02], [Roy05]). Although the language and communications of humans and machines differ significantly, their roles are similar. More specifically, Haikonen [Haik03], [Haik04] defines cognition as the association of auxiliary meanings with percepts, the use of percepts as symbols, the manipulation of these symbols, reasoning, response generation, and language. He defines five classes of such behavioural machines: (i) simple-reflex machine (RM1), (ii) RM1 with smart memory (RM2), (iii) perceptual machine with associative memory and meaningful perception (PM1), (iv) perceptual machine like PM1, but with reporting (PM2), and (v) cognitive machine with self-awareness and mind (CM). The models require no rule-based artificial intelligence, no need for neural networks, and spontaneous emergent processes in dynamic systems, without their programming into the machines.

At the beginning of $2000 \mathrm{~s}$, much attention was given to autonomic computing to increase reliability, robustness, dynamic flexibility, and to reduce maintenance cost of computing systems (e.g., [GaCo03], [Kins05a], [Wang03], [Wang04], [Wang06]). Although autonomic computing is not cognitive computing or a cognitive system, it includes many features that will also be found in cognitive systems. Its features include: selfupdating, self-configuring, self-optimizing, selforganizing, self-healing, self-protecting, and selfcommunicating.

\subsection{Examples of Cognitive Systems}

Haykin [Hayk05a] defines cognitive radio as a system capable of sensing the environment, as well as channel-state estimation and predictive modelling for decision making and action, as illustrated in Fig. 1.

As mentioned in Sec. 1, there are many other examples of cognitive systems, including cognitive radar [Hayk06], active audition [HaCh05], cognitive networks [HoBF 12], [HoBh10], [HNZH09], cognitive DNA analysis [KiZh10], cognitive control [HFSX12], and cognitive robots [Wang10a], [Wang10b].

\subsection{Cognitive Dynamic Systems}

In his book on cognitive dynamic systems [Hayk12], Haykin defines a cognitive dynamic system as a system that builds up its rules of behaviour over time through learning from continuous experiential interactions with the environment, and thereby deals with environmental uncertainties.

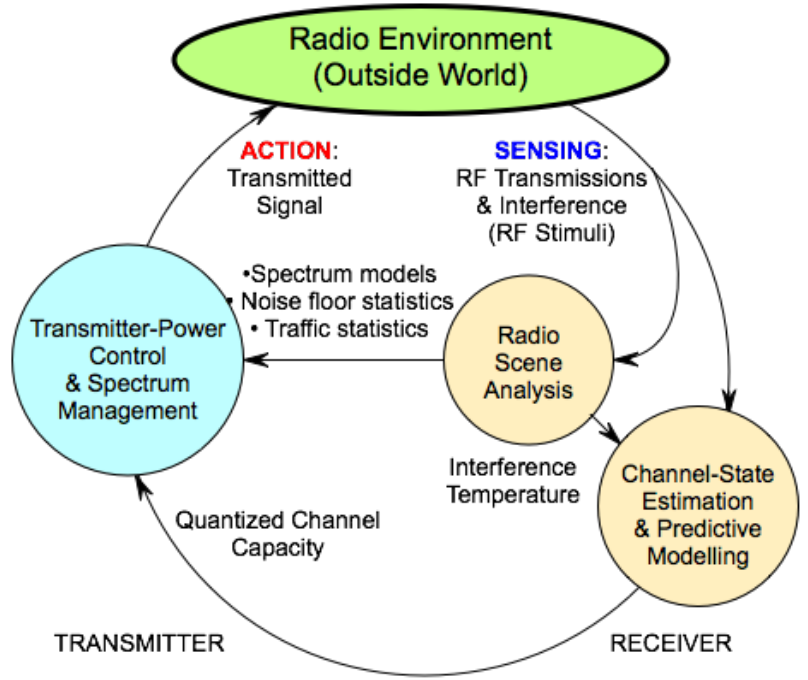

Fig. 1. Cognitive radio: A cognitive cycle for transceivers (After [Hayk05a]).

The key ideas behind the CogSys definition are: (i) awareness of the environment, (ii) intelligence, (iii) learning, (iv) adaptivity, (v) action, (vi) real-time or hyper-real-time [Doug99] operation. The main limitation of the definition is that emphasis is given to the individual traits, thus leading to competition. Societal emphasis should be added to enhance cooperation and symbiotic co-existence.

\section{TEACHING OF COGNITIVE DYNAMIC SYSTEMS}

\subsection{Cognitive Engineering}

Modelling of cognitive systems (CogSys) is often in the domain of computer science, computer engineering, electrical engineering, control engineering, mechanical engineering, mechatronics, and others. In addition to modelling of CogSys, we are often interested in the engineering approach, as this approach produces specific implementations that should be human-centric. In fact, one of the practical goals of CogSys is the eradication of user-hostile systems that force us to adapt and devise local kludges and workarounds. Machines should adapt to people, and not the other way around (i.e., CogSys must be human-centered) [HoKL02], [HoWo05]. CogSys should empower people in their 
perceptual, cognitive and collaborative skills, interactions, and work. They should also enhance our education, health care, and entertainment. This engineering approach to modelling, designing, implementing, verification and testing of cognitive systems could be termed cognitive engineering (CogEng) [HoWo05].

Teaching CogEng as a discipline may not be plausible at this time, as many more theoretical and design challenges must be solved first [Kins09]. However, subsets of topics can be taught in specific departments now.

\subsection{Engineering Design Process (EDP)}

Design is contextual. For example, design in applied and fine arts is different from that in architecture or engineering. Engineering design is the process of developing an artefact that satisfies specific requirements and budget. The design process is based on at least two characteristics: (i) philosophy (e.g., [Koen03], [EdHo08]) and (ii) a collection of steps that guide the designer or a team from the concept to the implementation, verification and testing in the field (e.g., [CEAB06/12], [ABET06/12], [ITEA07/12]). Teaching design must involve both the methodological and innovative approaches [DWCP02].

Engineering design has at least two approaches [Cros00]: (i) prescriptive (algorithmic, sequential, linear) in simple, well-established designs, with a few conditions satisfied [Kins09], and (ii) descriptive (openended, holistic, gestalt) for most successful designs. The gestalt model for cognitive engineering design for nonsequential, non-linear process, with future impact considered at each stage is shown in Fig. 2 [FoCo00], [Kins09].

Other design models are discussed in [Kins09], including the fountain model for software design [HeEd90], and the co-design model for embedded systems (e.g., [GVNG94], [Valv00], [VaGi02], [Kama08]).

These engineering design processes (EDPs) have been used for decades. When a weakness is discovered in a specific EDP, it is improved. So, seemingly, there is no problem for ordinary engineering designs. However, when the system becomes cognitive, with emergence, the existing EDPs become inadequate.

Let us examine the strengths and weaknesses of the post-secondary educational system as implemented today, and how to enhance it.

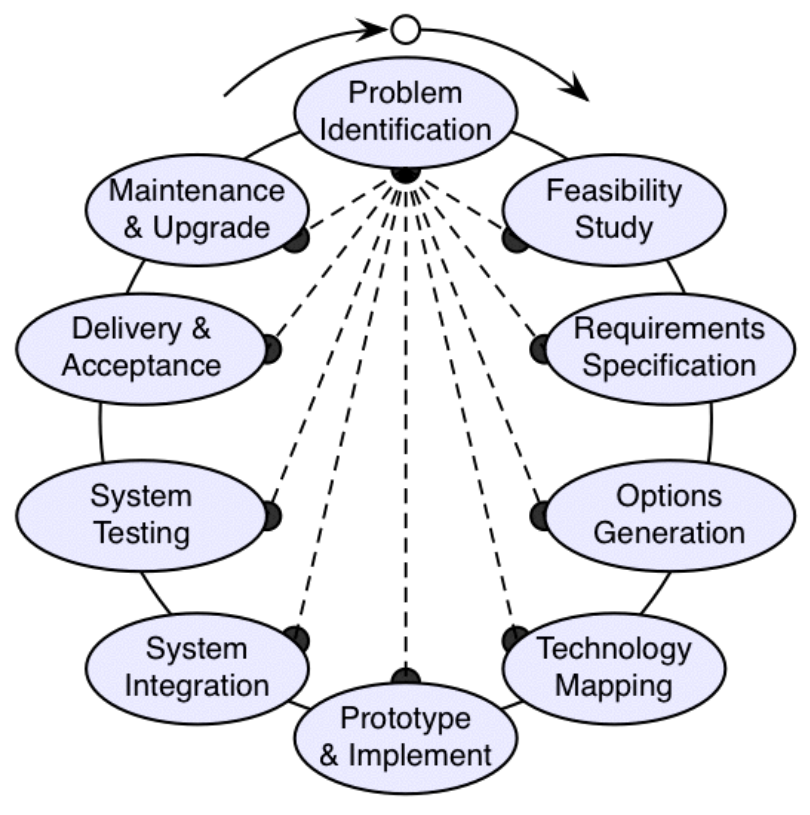

Fig. 2. A gestalt approach to the engineering design process. (After [FoCo00]; p. 4)

\subsection{Foundation for EDP}

University engineering programs have been developed to provide our students with very extensive exposure to the methodological engineering design process (EDP). The programs provide solid background and foundation in (i) mathematics (algebra, calculus, analysis, numerical math, discrete math); (ii) basic sciences (physics, chemistry, geology \& environmental sciences); (iii) basic engineering sciences (electromagnetism, circuit theory, linear control theory [Zak03], electronics, information theory, computing, embedded processing, signal acquisition and validation, signal \& image processing, pattern recognition, computer networking, with algorithms such as Kalman filtering and Bellman's linear programming playing prominent roles); and (iv) specialized engineering sciences (statistical signal processing, statistical control with Gaussian probability distributions).

Since the real world appears to be mostly nonlinear and non-Gaussian [Enns10], the above exposure alone cannot convert a student into an engineer who designs well. Thus, not only the methodological design approach, but also the innovative design approach is necessary in that evolution of a student. A possible two-prong approach might involve (i) an extended foundation and (ii) experiential learning. How can we best intertwine the methodological and innovative design approaches, and present that unified approach to our students? 


\subsection{Extended Foundation for EDP}

The design of intelligent and cognitive systems requires a major extension of the topics taught in our current programs. The extension should affect the following major areas:

1. Extended Discrete Mathematics. Examples include:

- Fuzzy computing, rough computing [Paw191];

- Granular computing [Pedr01], [BaPe03];

- Self-affinity (fractality and multifractality) [PeJS92], [Kins13];

- Multiscale analysis and synthesis [Warn96];ß

- Higher-order statistics [HyKO01];

- Automata theory; binary decision diagrams [Kins11];

- Optimization of large systems [Kins11];

- Intelligent agents;

- Shannon and non-Shannon entropies [GeTs04], [Down11], [Kins13];

- Complexity theory [Main04], [Erdi08], [Mich09], [Kins10];

- Self organization [Koho87], [Wall00];

- Emergent computation;

- Cognitive informatics [Wang02a], [Wnag06].

2. Intelligent Signal Processing [HPSM06], [HyKO01]. For example,

- Intelligent sampling, compressed sensing [ElKu12];

- Non-parametric models [KaSc04];

- Time-scale and wavelet models [Mal198];

- Multiscale models [GCTH07], [BuKB12];

- Polyscale (fractal and multifractal) models [Kins05b], [Kins11];

- Long-range-dependence patterns in the data [KaSc04], [Spro03].

3. Nonlinear Control. For example,

- Nonlinear dynamical systems [Jack91];

- Cognitive dynamic systems [Hayk12];

- Chaotic systems [Strog94], [OtSY94].

4. Nonlinear Computing Paradigms. For example,

- Structural computing (neural networks with recurrence);

- Machine learning [Bish04];

- Statistical learning theory;

- Biomolecular and quantum computing.

5. Biology-Motivated Algorithms

- Biology for engineers [Mann12];

- Bioinformatics;

- Neuroscience;
- Game theory.

\subsection{Experiential Learning}

Experiential learning is the process of fusion of the theory (obtained by individual students in the classroom) with practice (obtained by either individual students in innovative laboratories or co-op and internship programs, as well as by teams of students in capstone design projects, workshops and large projects). Recent changes to the attribute-based outcome-driven engineering education in Canada have accelerated the experientialbased learning (e.g, [SpFi12]). The changes were motivated by various concerns articulated by industry. Companies do not tolerate extended years of on-the-job training for new graduates due to: short product life cycles, and fast turn-around of employees ( 7 years to just months in California).

Undergraduate Discovery Labs: Example of experiential learning include two first-year courses with many "discovery" lab/projects [ShKo12] [BoDo12], and a course in sensors, measurement and instrumentation [ChGO12]. Engineers teaching technical communication to students is described in [DEKL12]. An example of meaningful learning is described in [AlStr12]. Multi-tier laboratories have also been introduced, with Tier1 representing the standard labs, Tier2 more advanced projects, and Tier3 open-ended projects in order to distinguish between different levels of experience among students [KiBr01]. Work is also done to acquire smaller and less expensive test devices such as oscilloscopes and logic/protocol analyzers so that students could perform the labs at home and demonstrate the results in the supervised lab [ScKM11].

Graduate Discovery Labs: Another example of a graduate course special demonstration instrument is described in [ByKi12]. Teaching undergraduate and graduate engineering students in a classroom environment usually involves a number of techniques, including oral presentations and discussions, visual materials (images and video) to augment difficult ideas, written homework, quizzes, tests, and exams, as well as hands-on laboratories. Classroom demonstrations of existing artefacts (chips, processors, boards, electromechanical devices, subsystems and systems) may also be very effective. Of particular importance are demonstrations developed specifically for the course by course participants, as they understand the challenges in acquiring difficult material.

In the case of dynamical systems (i.e., nonlinear dynamic systems that can exhibit chaos), the material taught requires considerable sophistication from the students, and explanations by traditional techniques may not be adequate [Kins12]. Consequently, using 
demonstrations of real examples of dynamical systems can ease the understanding of the underlying concepts, particularly when the demonstrations can behave in a fully-controlled fashion.

There are many such examples of dynamical systems that can be used for demonstration. However, there are only a few nonlinear systems that satisfy the following three key requirements simultaneously: (i) they can be described by an appropriate mathematical model (e.g., differential equations), (ii) can be modelled on a computer, and (iii) can be implementable in the laboratory for classroom demonstrations and research. Such examples should also satisfy additional requirements, including: (i) be inexpensive to implement with commercial off-the-shelf (COTS) components, (ii) easy to maintain, (iii) easy to modify, (iv) durable in multiple use, and should be easy to monitor without affecting the quality of the measured signal (dynamical systems are sensitive to initial conditions and thus to sensor probes).

\section{Student-Run and Professor-Run Extra Workshops}

Students can also extend their experiential learning by running workshops (e.g., [SDSW12]). Professors also supplement the experiential learning by presenting specialized courses (e.g., on ham radio theory and practice) and related workshops.

Capstone Team Design Projects: Capstone projects are mandatory in most accredited universities. The current shift from the individual graduating thesis to a group capstone design project has been implemented in Canada and elsewhere to teach not only the necessary hard, but also many soft skills. Although there are many models for the projects, they engage teams of students to design, implement and test complex projects [SSNK09]. The monitoring of the projects by departments is designed to assure high-quality outcomes for the students involved. We have also tried to create teams from different programs and departments.

Team of Teams Projects: A major example of experiential learning is the development of the first University of Manitoba functional triple pico-satellite (code T-Sat1) as part of the Canadian Satellite Design Challenge [SAFG12]. The project attracted over 100 undergraduate and graduate students from five faculties and 16 departments. The TSat 1 students were supported by over 50 advisors from academia, aerospace industry, various businesses, military, government, and radio community [SAFR12]. This project was also supported by Friends of Engineering who also play an important experiential role for many other projects [BrSR12].

Co-Op Program: In order to provide the best on-the-job experiential learning for our students, the Faculty of
Engineering has revamped the co-op program to include rotating co-op (from 4 to 8 to 16 months periods).

Support of Aboriginal Students and IEEQ: For years, the University of Manitoba has been supporting Aboriginal students through an elaborate Engineering Access Program (ENGAP) [Herr12], and Internationally Educated Engineers to advance their qualifications through an IEEQ program [FrBa12].

Pre-University Activities: An example of experiential learning for university students is through pre-university activities such as (i) workshops to high-school students [SAFL12], and (ii) a summer Space Camp [KBCE11].

\section{CONCLUDING REMARKS}

Cognition is a transformative technology which is applicable to a multitude of engineering systems, both old and new. Cognitive dynamic systems (CogSys) have opened up a new landscape for exciting new concepts, new research projects, and new development projects.

However, teaching engineering design of CogSys is very challenging. Cognitive dynamic systems require some of the most sophisticated concepts and algorithms available today, including: (i) extended discrete mathematics (ii) intelligent signal processing, (iii) nonlinear control, (iv) nonlinear computing paradigms, and (v) biology-motivated algorithms.

It should be noticed that not all engineers, researchers, and educators subscribe to the notion of cognitive dynamic systems, as not all advocate the set of topics suggested for teaching the subject. For example, in his review of a very important book on tracking and multisensory data fusion algorithms [BaWT11], Daum [Daum12] states "this book scrupulously avoids any mention of non-Bayesian methods such as fuzzy sets, Dempster-Shafer theory, wavelets, chirplets, tracklets, chicklets, neural nets, fractal chaotic catastrophe theory, and topological computation theory...". His preferred treatment of such algorithms is purely Bayesian, and includes: limited-resolution of the sensors, data association errors, measurement-noise-errors of the sensors, residual sensor bias and drift errors, measurement errors due to the propagation through the physical environment, clutter, jamming, multipath, nonzero probability of false alarms, non-unity probability of detection of the targets, ill conditioning of the error covariance matrix of the extended Kalman filter, nonlinearities in the sensors measurements and dynamics of the targets, unmodelled dynamics of the target motion, real-time computational complexity of the algorithms, real-time joint multiple sensor resource management, limited resolution of the sensors, nonGaussian multimodal probability densities of the estimate of the state vector and the sensor measurements, 
statistical inconsistency of covariance matrices of the sensor measurements and the state vector error covariance matrices from various sensors, random sets of hypotheses, robustness to uncertainty in the models of sensors and target dynamics and environment, quantification of system performance as a function of track rate, multiple sensor geometry, unmodelled target acceleration, signal-to-noise ratio, and spatial density of the targets, as well as the limited resolution of the sensors. It is inspiring that all these topics are treated using Bayesian approaches. However, these issues are not related to cognitive dynamical systems directly. The availability of the textbooks and monographs listed in this paper will probably help in teaching the extensions to the fundamentals of CogSys design.

\section{Acknowledgements}

We would like to thank the Department of Electrical and Computer Engineering and the Faculty of Engineering, University of Manitoba for supporting various activities described in this paper. Special thanks go to the Aerospace Manitoba, University of Manitoba Space Applications and Technology Society (UMSATS), IEEE McNaughton Student Centre (UMIEEE), University of Manitoba Amateur Radio Society (UMARS) and other organizations for partial support of these projects.

\section{References}

[ABET06] ABET: Engineering Accreditation Commission: Criteria for accreditation engineering programs. Report, 2006, 29 pp. Retrieved June 2007, from

http://www.abet.org/forms.shtml

[AlStr12] Richard Aleong and David Strong, "Engaging students in meaningful learning: Understanding student perspectives of engineering design education," in Proc. 2nd Canadian Engineering Education Association Conf., CEEA12, W. Kinsner (ed.) (Winnipeg, MB; June 17-20, 2012) ISBN 978-1927697-00-9, pp. 1-5, 2012.

[Ande05] James A. Anderson, “Cognitive computation: The Ersatz brain project: Keynote," in Proc. 4th IEEE Intern. Conf. Cognitive Informatics, ICCI05, (Irvine, CA; August 8-10, 2005) ISBN 1-7803-9136-5, pp. 2-3, 2005.

[ATVY12] Alireza Attar, Helen Tang, Athanasios V. Vasilakos, F. Richard Yu, and Victor C.M. Leung, "Asurvey of security challenges in cognitive radio networks: Solutions and future research directions," Proc. of the IEEE, vol. 100, no. 12, pp. 3172-3186, Dec 2012.
[BaPe02] Andrzej Bargiela and Witold Pedrycz, Granular Computing: An Introduction. New York, NY: Springer, 2002, 480 pp.

[BaWT11] Yaakov Bar-Shalom, Peter K. Willett, and Zin Tian, Tracking and data Fusion: Handbook of Algorithms. Bradford, UK: YBS Publishing, 2011, 1250 pp. \{ISBN-13: 978-0964831278\}

[Bish95] Christopher M. Bishop, Neural Networks for Pattern Recognition. Oxford, UK: Oxford Univ. Press, 1995, 482 pp.

[BoDo12] Jon-Michael J. Booth and Thomas E. Doyle, "Importance of first-year engineering design projects to self-efficacy: Do first-year students feel like engineers?" in Proc. 2nd Canadian Engineering Education Association Conf., CEEA12, W. Kinsner (ed.) (Winnipeg, MB; June 17-20, 2012) ISBN 978-1927697-00-9, pp. 162-169, 2012.

[BrSR12] Ron Britton, Amber Skrabek, and Doug Ruth, "Friends of Engineering: A positive connection with industry," in Proc. 2nd Canadian Engineering Education Association Conf., CEEA12, W. Kinsner (ed.) (Winnipeg, MB; June 17-20, 2012) ISBN 978-1927697-00-9, pp. 284-285, 2012.

[BuKB12] Ivo Bukovsky, Witold Kinsner, and Jiri Bila, "Multiscale analysis approach for novelty detection in adaptation plot," in Proc. 3rd 2012 IEEE Sensor Signal Processing for Defence, SSPD 2012 (Imperial College, London, UJ; September 25-27, 2012) 2012.

[ByKi12] Ahmad Byagowi and Witold Kinsner, "Implementation of a Chua circuit to demonstrate bifurcations and strange attractors in class," in Proc. 2nd Canadian Engineering Education Association Conf., CEEA12, W. Kinsner (ed.) (Winnipeg, MB; June 17-20, 2012) ISBN 978-1-927697-00-9, pp. 401410, 2012.

[CEAB06] CEAB: Canadian Engineering Accreditation Board: Accreditation criteria and procedures, (Report), 2006, 40 pp. Retrieved June 2007 from http://www.engineerscanda.ca/e/prog_publications_3. cfm

[Cha197] David Chalmers, The Conscious Mind: In Search of a Fundamental Theory. Oxford, UK: Oxford Univ. Press, 1997, 432 pp.

[ChGO12] Vincent Chan, Ahmad Ghasempoor, and Devin Ostrom, Design of an experiential learning course in sensors, measurement and instrumentation," in Proc. 2nd Canadian Engineering Education Association Conf., CEEA12, W. Kinsner (ed.) (Winnipeg, MB; June 17-20, 2012) ISBN 978-1927697-00-9, pp. 85-89, 2012.

[Chom06] Noam Chomsky, Language and Mind. Cambridge, UK: Cambridge Univ. Press, 2006 (3rd ed.), $208 \mathrm{pp}$.

[Cott88] Rodney Cotterill (ed.), Computer Simulations in Brain Science. Cambridge, UK: Cambridge Univ. Press, 1988, 566 pp.
CEEA Conf. 2012; Paper 119

Winnipeg, MB; June 17-20, 2012
ceea12-dynamic-Full-v54.docx May 6, 2012 
[Cros00] Nigel Cross, Design Methods: Strategies for Product Design. New York, NY: Wiley, 2000 ( $3^{\text {rd }}$ ed.), 224 pp. \{ISBN 0-471-87250-4\}

[DWCP02] Samantha De Bon, Deborah Wolfe, JeanYves Chagnon, and William G. Paterson, "Engineering Accreditation in Canada and Its current challenges," In Proc. 2002 ASEE/SEFI/TUB Colloquium, 9 pp. Retrieved May 2007 from http://www.asee.org/conferences/international/papers/ upload/Engineering-Accreditation-in-Canada-and-ItsCurrent-Challenges.pdf

[DEKL12] Kathleen Denbeigh, Ali Vahid Esensoy, Penny Kinnear, Jason Li, Wilson Ma, Michelle MacArthur, Asmaa Maloul, Mario Millisevic, Aaron H. Persad, Farzan Sasangohar, Deborah Tihanyi, and Liang (Leon) Yuan, "Engineers teaching engineering communication: Integrating disciplinary expertise into the engineering communication curriculum," in Proc. 2nd Canadian Engineering Education Association Conf., CEEA12, W. Kinsner (ed.) (Winnipeg, MB; June 17-20, 2012) ISBN 978-1-927697-00-9, pp. 141150, 2012.

[Denn91] Daniel C. Dennett, Consciousness Explained. London, UK: Allan Lane/Penguin, 1991, 528 pp.

[Doug99] B.P. Douglass, Doing Hard Time: Developing Real-Time Systems with UML, Objects, Frameworks, and Patterns. Reading, MA: Addison-Wesley, 1999, $749 \mathrm{pp}$.

[Daum12] Fred Daum, "Tracking and data fusion: Handbook of algorithms," Book Review. IEEE Aerospace and Electronic Systems Mag., pp. 34-35, Dec 2012.

[Down11] Tomasz Downarowicz, Entropy in Dynamical Systems. Cambridge, UK: Cambridge University Press, 2011, 391 pp. \{ISBN 978-0-521-88885-1 hbk

[EdHo08] W. Ernst Eder and Stanislav Hosnedl, Design Engineering: A Manual for Enhanced Creativity. Boca Rayton, FL: CRC, 2008, 588 pp.

[ElKu12] Yonina C. Eldar and Gitta Kutyniok (eds.), Compressed Sensing: Theory and Applications. Cambridge, UK: Cambridge University Press, 2012, 544 pp.

[Enns10] Richard H. Enns, It's a Nonlinear World. New York, NY: Springer, 2010, 383 pp. \{ISBN 978-0-38775338-6

[Erdi08] Péter Érdi, Complexity Explained. New York, NY: Springer, 2008, 397 pp. \{ISBN 978-3-54035777-3\}

[FiFi87] Martin A. Fischler and Oscar Firschein, Intelligence: The Eye, The Brain and the Computer. Reading, MA: Addison-Wesley, 1987, 331 pp.

[FoCo00] Ralph M. Ford and Chris S. Coulston, Design for Electrical and Computer Engineers: Theory, Concepts, and Practice. New York, NY: McGraw Hill (Custom Publishing), 2000, 280 pp.
[FrKa99] Menahem Friedman and Abraham Kandel, Introduction to Pattern Recognition: Statistical, Structural, Neural, and Fuzzy Logic Approaches. London, UK: Imperial College Press/World Scientific, 1999, 329 pp.

[FrBa12] Marcia Friesen and Catherine Baxter, "A qualifications recognition program for Internationally Educated Engineers: A model and critical perspectives," in Proc. 2nd Canadian Engineering Education Association Conf., CEEA12, W. Kinsner (ed.) (Winnipeg, MB; June 17-20, 2012) ISBN 978-1927697-00-9, pp. 277-283, 2012.

[GVNG94] Daniel D. Gajski, Frank Vahid, Sanjiv Narayan, and Jie Gong, Specification and Design of Embedded Systems. Englewood Cliffs, NJ: PTR Prentice Hall, 1994, 450 pp.

[GaCo03] A.G. Ganek and T.A. Corbi, "The dawning of the autonomic computing era," IBM Systems J., vol. 42, no. 1, pp. 34-42, 2003. (Available as of May 2006 from

http://www.research.ibm.com/journal/sj/421/ganek.pd f)

[GCTH07] Jiabo Gao, Yinhe Cao, Wen-wen Tung, and Jing $\mathrm{Hu}$, Multiscale Analysis of Complex Time Series: Integration of Chaos and Random Fractal Theory, and Beyond. Hoboken, NJ: Wiley, 2007, 352 pp. \{ISBN 978- 0-471-65470-4\}

[GeTs04] Murray Gell-Mann and Constantino Tsallis (eds.), Nonextensive Entropy: Interdisciplinary Applications. Oxford, UK: Oxford Univ. Press, 2004, 422 pp. \{ISBN 0-19-515976-4 hbk\}

[Haik03] Pentti O. Haikonen, The Cognitive Approach to Conscious Machines. New York, NY: Academic, 2003, 294 pp.

[Haik04] Pentti O.A. Haikonen, "Conscious machines and machine emotions," Workshop on Models for Machine Consciousness (Antwerp, BE; June 2004) 2004.

[Haik07] Pentti O. Haikonen, Robot Brains: Circuits and Systems for Conscious Machines, Wiley, 2007, 225 pp. \{ISBN: 978-0-470-06204-3\} (See also http://personal.inet.fi/cool/pentti.haikonen/)

[Hayk05a] Simon Haykin, "Cognitive radio: Brainempowered wireless communications," IEEE J. Selected Areas in Communications, vol. 23, no. 2, pp. 201-220, February 2005.

[Hayk05b] Simon Haykin, "Cognitive machines," in IEEE Intern. Workshop on Machine Intelligence \& Sign. Proc., IWMISP05 (Mystic, CT; September 2830, 2005), 2005. Available as of May 2006 from http://soma.crl.mcmaster.ca/ASLWeb/Resources/data/ Cognitive_Machines.pdf

[Hayk06] Simon Haykin, "Cognitive radar," IEEE Signal Processing Mag., pp. 30-40, January 2006.

[Hayk12] Simon Haykin, Cognitive Dynamic Systems: Perception-Action Cycle, Radar and Radio. 
Cambridge, UK: Cambridge University Press, 2012, $322 \mathrm{pp}$.

[HaCh05] Simon Haykin and Zhe Chen, "The cocktail party problem," Neural Computation, vol. 17, pp. 1875-1902, 2005.

[HaKo01] Simon Haykin and Bart Kosko, Intelligent Signal Processing. New York, NY: Wiley-IEEE, 2001, $573 \mathrm{pp}$.

[HPSM06] Simon Haykin, José C. Principe, Terrence J. Sejnowski, and John McWhirter, New Directions in Statistical Signal Processing. Cambridge, MA: MIT Press, 2006, 544 pp.

[HFSX12] Simon Haykin, Mehdi Fatemi, Peyman Setoodeh, and Yanbo Xue, "Cognitive control," Proc. of the IEEE, vol. 100. no. 12, pp. 3156-3169, Dec 2012.

[HeEd90] Brian Henderson-Sellers and Julian M. Edwards, "The object-oriented systems life cycle," Communications of the ACM, vol. 33, no. 9, pp.142159, Sep 1990.

[Herr12] Randy Herrmann, "The application of support mechanisms to increase the success of Aboriginal students," in Proc. 2nd Canadian Engineering Education Association Conf., CEEA12, W. Kinsner (ed.) (Winnipeg, MB; June 17-20, 2012) ISBN 978-1927697-00-9, pp. 392-394, 2012.

[HoKL02] Robert R. Hoffman, Gary Klein, and K. Ronald Laughry, "The state of cognitive systems engineering," IEEE Intelligent Systems Mag., pp. 7375, January/February 2002.

[HoWo05] Erik Hollnagel and David D. Woods, Joint Cognitive Systems: Foundations of Cognitive Systems Engineering. Boca Raton, FL: CRC Press/ Taylor \& Francis Group, 2005, 223 pp. \{ISBN 978-0-84932871-8 hbk .

[HyKO01] Aapo Hyvarinen, Juha Karhunen, and Erkki Oja, Independent Component Analysis. New York, NY: Wiley, 2001, 481 pp.

[IBM06] IBM Autonomic Computing Manifesto. Available as of May 2006 from http://www.research.ibm.com/autonomic/

[ITEA07] ITEA: International Technology Education Association: Glossary terms for STL and AETL and Addenda, Report, 2007, 30 pp. (STL -Standards for Technological Literacy; AETL -Advancing Excellence in Technological Literacy; TAA Technology for All Americans) Retrieved June 2007 from $<$ http://www.iteaconnect.org/TAA/Publications/TAA_ Publications.html>

[Jack91] E. Atlee Jackson, Perspectives of Nonlinear Dynamics. Cambridge, UK: Cambridge Univ. Press, 1991, Vol. 1, 496 pp. \{ISBN 0-521-42632-4 pbk\} and Vol. 2, 633 pp. \{ISBN 0-521-42633-2 pbk\}
[Kama08] Raj Kamal, Embedded Systems: Architecture, Programming, and Design. New York, NY: McGrawHill, 2008, 633 pp. \{ISBN 0-07-340456-X\}

[KaSc04] Holger Kantz and Thomas Schreiber, Nonlinear Time series Analysis. Cambridge, UK: Cambridge Univ. Press, 2004 (2nd ed.), 369 pp.

[Kins05a] Witold Kinsner, "Signal processing for autonomic computing," in Proc. 2005 Meet. Can. Applied \& Industrial Math Soc., CAIMS 2005 (Winnipeg, MB; June 16-18, 2005) 2005. Available as of May 2006 from http://www.umanitoba.ca/institutes/iims/caims2005_t heme_signal.shtml

[Kins05b] Witold Kinsner, "A unified approach to fractal dimensions," in Proc. IEEE 2005 Intern. Conf. Cognitive Informatics, ICCI05 (Irvine, CA; August 810, 2005), pp. 58-72, 2005 \{ISBN: 0-7803-9136-5\}

[Kins06] Witold Kinsner, "Towards cognitive machines: Multiscale measures and analysis," Intern. J. Cognitive Informatics and Natural Intelligence, vol. 1, no. 1, pp. 28-38, 2006.

[Kins08] Witold Kinsner, "A unified approach to fractal dimensions," J. Information Technology Research (JITR), vol. 1, no. 4, pp. 62-85, Oct-Dec 2008.

[Kins09] Witold Kinsner, "Challenges in the design of adaptive, intelligent and cognitive systems," Intern. $J$. Software Science \& Computational Intelligence, vol. 1, no. 3, pp. 16-35, July-Sept. 2009.

[Kins10] Witold Kinsner, "System complexity and its measures: How complex is complex," in Yingxu Wang, Du Zhang, and Witold Kinsner (eds.), Advances in Cognitive Informatics and Cognitive Computing. Berlin: Springer Verlag, Vol SCI 323, pp. 265-295, 2010. \{ISBN 978-3-642-16082-0; eISBN 978-3-642-16083-7\}

[Kins11] Witold Kinsner, Switching and Automata Theory. Lecture Notes. Winnipeg, Manitoba: University of Manitoba, 2011, $874 \mathrm{pp}$.

[Kins12] Witold Kinsner, "Towards cognitive security systems," in Proc. of the 11 th IEEE Intern. Conf. on Cognitive Informatics and Cognitive Computing, ICCI*CC 2012, (Kyoto, Japan; August 22-24, 2012), 2012, (Keynote Speech).

[Kins13] Witold Kinsner, Fractal \& Chaos Engineering. Lecture Notes. Winnipeg, Manitoba: University of Manitoba, 2013, 941 pp.

[KiBr01] Witold Kinsner and Kalen Brunham, "A multitier laboratory scheme in the interfacing for real-time systems course," in Proc. 14th Can. Conf. Computer Engineering Education, CCCEE01 (Fredericton, NB; May 30-June 1, 2001) 64 pp., 2001.

[KiZh10] Witold Kinsner and Hong Zhang, "Multifractal analysis for feature extraction from DNA sequences," Intern. J. Software Science and Computational Intelligence, vol. 2, no. 2, pp. 1-18, Apr-Jun 2010.
CEEA Conf. 2012; Paper 119

Winnipeg, MB; June 17-20, 2012
ceea12-dynamic-Full-v54.docx -9 of $12-$
May 6, 2012 
[KBCE11] Witold Kinsner, M.G.(Ron) Britton, Jeff Cieszecki, Wayne Ellis, Alan Thoren, Dario Schor, Brian Statham, Greg Linton, Tom Tessier, Rob Striemer, Colleen Flather, Barbara Bowen, and Norman Lee, "A space adventure camp and preuniversity outreach," in Proc. CEEA Canadian Engineering Education Conf., CEEC11 (St. John's, NL; 6-8 June 2011), 8 pp., 2011.

[Kliv89] Kenneth Klivington, The Science of Mind. Cambridge, MA: MIT Press, 1989, 239 pp.

[Koen03] Billy Vaughn Koen, Discussion of the Method: Conducting the Engineer's Approach to Problem Solving. Oxford, UK: Oxford University Press, 2003, 260 pp. \{ISBN 0-19-515599-8 pbk\}

[Koho87] Teuvo Kohonen, Self-Organization and Associative Memory. New York, NY: Springer Verlag, 1987 (2nd ed.), 312 pp.

[Kurz90] Raymond Kurzweil, The Age of Intelligent Machines. Cambridge, MA: MIT Press, 1990, 565 pp.

[Main04] Klaus Mainzer, Thinking in Complexity: The Computational Dynamics of Matter, Mind, and Mankind. New York, NY: Springer, 2004 ( $4^{\text {th }}$ ed. $)$, 456 pp. \{ISBN 3-540-00239-1\}

[Mal198] Stéphane Mallat, A Wavelet Tour of Signal Processing. San Diego, CA: Academic Press, 1998, $577 \mathrm{pp}$.

[Mann02] Steve Mann, Intelligent Image Processing. New York, NY: Wiley/IEEE, 2002, 342 pp.

[Mann12] Danny Mann, "The role of biology in an Engineering Program," in Proc. 2nd Canadian Engineering Education Association Conf., CEEA12, W. Kinsner (ed.) (Winnipeg, MB; June 17-20, 2012), pp. 382-386, 2012.

[Mins86] Marvin Minsky, The Society of Mind. New York, NY: Touchstone, 1986, 339 pp.

[Mich09] Melanie Mitchell, Complexity: A Guided Tour. Oxford, UK: Oxford Univ. Press, 2009, 349 pp.

\{ISBN 978-0-19-512441-5 hbk\}

[Neum58] John von Neumann, The Computer and the

Brain. New Haven, CT: Yale Univ. Press, 1958, 82 pp.

[NiCh00] Michael A. Nielsen and Isaac L. Chuang, Quantum Computation and Quantum Information. Cambridge, UK: Cambridge Univ. Press, 2000, 676 pp.

[OtSY94] Edward Ott, Tim Sauer, and James A. Yorke (eds.), Coping with Chaos: Analysis of Chaotic Data and the Exploitation of Chaotic Systems. New York, NY: Wiley, 1994, 418 pp. \{ISNBN 0-471-02556-9\}

[Pars05] Mitch Parsell, "Review of P.O. Haikonen, The Cognitive Approach to Consious Machines," Psyche, vol. 11. no. 2, pp. 1-6, March 2005. Available as of May 2006 from http://psyche.cs.monash.edu.au/book_reviews/haikone n/haikone.pdf
[Paw191] Zdzislaw Pawlak, Rough Sets: Theoretical Aspects of Reasoning about Data. New York, NY: Springer, 1991, 252 pp.

[PeJS92] H.-O. Peitgen, H. Jurgens and D. Saupe, Chaos and Fractals: New Frontiers of Science. New York (NY): Springer Verlag, 1992 ( $1^{\text {st }}$ ed.), 984 pp.; 2004 ( $2^{\text {nd }}$ ed.), 864 pp. \{ISBN 0-387-20229-3\}

[Penr89] Roger Penrose, The Emperor's New Mind. Oxford, UK: Oxford Univ. Press, 1989, 480 pp.

[Penr94] Roger Penrose, The Shadows of the Mind: A Search for the Missing Science of Consciousness. Oxford, UK: Oxford Univ. Press, 1994, 457 pp.

[PfSc99] Rolf Pheifer and Christian Scheier, Understanding Intelligence. Cambridge, MA: MIT Press, 1999, 720 pp.

[Posn89] Michael Posner (ed.), Foundations of Cognitive Science. Cambridge, MA: MIT Press, 1989, 888 pp.

[Pedr01] Witold Pedrycz, Granular Computing: An Emerging Paradigm. New York, NY: Springer, 2001, 397 pp.

[PeGo98] W. Pedrycz and F. Gomide, An Introduction to Fuzzy Sets: Analysis and Design. Cambridge, MA: MIT Press, 1998, 465 pp.

[RaRH03] Anthony Ralson, Edwin D. Reilly, and David Hemmendinger (eds.), Encyclopedia of Computer Science. New York, NY: Wiley, 2003 (4th ed.), 2064 pp.

[Roy05] Deb K. Roy, "Grounding words in perception and action: Insight for computational models," Trends in Cognitive Sciences, vol. 9, no. 8, pp. 389-396, August 2005.

[RoPe02] Deb K. Roy and A.P. Pentland, "Learning words from sights and sounds: A computational model," Cognitive Science, vol. 26, pp. 113-146, 2002.

[RuBT05] Maria E. Ruaro, Paolo Bonifazi, and Vincent Torre, "Toward the neurocomputer: Image processing and pattern recognition with neuronal cultures," IEEE Trans. Biomedical Eng., vol. 52, no. 3, pp. 371-383, March 2005.

[RuMc86] David E. Rumelhart and James L. McClelland, Parallel Distributed Processing. Vols. 1 and 2. Cambridge, MA: MIT Press, 1986, 547 and 611 pp., respectively.

[SAFG12] Dario Schor, Kane Anderson, Cody Friesen, Kris Goodmanson, Morgan May, Arash Fazel-

Darbandi, Witold Kinsner, Ron Britton, and Malcolm Symonds, "Complex system design exposure through a satellite design competition," in Proc. 2nd Canadian Engineering Education Association Conf., CEEA12, W. Kinsner (ed.) (Winnipeg, MB; June 17-20, 2012) ISBN 978-1-927697-00-9, pp. 16-20, 2012.

[SAFL12] Dario Schor, Kane Anderson, Mohammadreza Fazel-Darbandi, Greg Linton, Matthew Woelk, Cody Friesen, Scott McKay, Katrina Soriano, Chad Stasiuk, Johnson Vilayvanh, Brendan 
Cade, David Terrazas, Troy Denton, Stephanie Reid, Witold Kinsner, Ron Britton, Dave Weichel, Debbie Leiter, Rob Striemer, and Norman Lee, "Preuniversity outreach through a satellite design competition," in Proc. 2nd Canadian Engineering Education Association Conf., CEEA12, W. Kinsner (ed.) (Winnipeg, MB; June 17-20, 2012) ISBN 978-1927697-00-9, pp. 338-343, 2012.

[SAFR12] Dario Schor, Kane Anderson, Cody Friesen, Stephanie Reid, Brady Russell, Mohammadreza Fazel-Darbandi, Arash Fazel-Darbandi, Witold Kinsner, Ron Britton, Malcolm Symonds, Diane Kotelko, Philip Ferguson, Raymoond Harris, Walter Czyrnyj, Samuel Kovnats, Maia Schor, Alan Thoren, and Brendan Hughes, "Enhanced student performance through industry advisors," in Proc. 2nd Canadian Engineering Education Association Conf., CEEA12, W. Kinsner (ed.) (Winnipeg, MB; June 17-20, 2012) ISBN 978-1-927697-00-9, pp. 90-93, 2012.

[SDSW12] Dario Schor, Troy Denton, Matthew Sebastian, Matthew Woelk, Frank Serafin, Craig Nemeth, Pawel Glowacki, Kiral Poon, Kane Anderson, Greg Linton, Arash Fazel-Darbandi, Witold Kinsner, Allan McKay, Kenneth Biegun, and Udaya Annakkage, "Complementing classroom experience with student-run workshops," in Proc. 2nd Canadian Engineering Education Association Conf., CEEA12, W. Kinsner (ed.) (Winnipeg, MB; June 17-20, 2012) ISBN 978-1-927697-00-9, pp. 416-420, 2012.

[ScKM11] Dario Schor, Witold Kinsner, and Kathryn Marcynuk, "Reinforcing the design foundation of asynchronous serial data communications using logic and protocols analyzers," in Proc. CEEA Canadian Engineering Education Conf., CEEC11 (St. John's, NL; 6-8 June 2011), 6 pp., 2011.

[SSNK09] D. Schor, J. Scowcroft, C. Nichols, and W. Kinsner, "A command and data handling unit for pico-satellite missions," in Proc. IEEE Canadian Conference on Electrical and Computer Engineering, CCECE09 (St. John's, NL; May 3-6, 2009), pp. 874879, 2009.

[Schw12] Mischa Schwartz, "Some thoughts on the communications field: The past and the present," Proc. of the IEEE, vol. 100, no. 12, pp. 3150-3151, Dec 2012.

[Sear80] John R. Searle, "Minds, brains and programs," Behavioral \& Brain Sciences, vol. 3, pp. 417-424, 1980.

[Sear92] John R. Searle, The Rediscovery of the Mind. Cambridge, MA: MIT Press, 1992, 288 pp.

[SARC03] Tanya Sienko, Andrew Adamatzky, Nichols

G. Rambidi, and Michael Conrad, Molecular Computing. Cambridge, MA: MIT Press, 2003, 257 pp.

[ShKo12] Cyrus Shafai and Behzad Kordi, "A laboratory-centered approach to introducing engineering students to electric circuit and electric systems concepts," in Proc. 2nd Canadian Engineering Education Association Conf., CEEA12, W. Kinsner (ed.) (Winnipeg, MB; June 17-20, 2012) ISBN 978-1-927697-00-9, pp. 63-67, 2012.

[SkWa10] Andrzej Skowron and Piotr Wasilewski, “An Introduction to Perception Based Computing," in Taihoon Kim, Young-hoon Lee, Byeong-Ho Kang and Dominik Slezak (eds.), Future Generation Information Technology, Lecture Notes in Computer Science, vol. 6485. New York, NY: Springer, pp. 1225, 2010.

[Solo99] Sabrie Soloman, Sensor Handbook. New York, NY: McGraw-Hill, 1999, 1486 pp.

[SpFi12] Darlene Spracklin-Reid and Andy Fisher, "Course-based learning outcomes as the foundation for assessment of graduate attributes," in Proc. 2nd Canadian Engineering Education Association Conf., CEEA12, W. Kinsner (ed.) (Winnipeg, MB; June 1720, 2012), pp. 255-257, 2012.

[Spro03] Julien C. Sprott, Chaos and Time-Series Analysis. Oxford, UK: Oxford Univ. Press, 2003, 507 pp.

[Strog94] Steven H. Strogatz, Nonlinear Dynamics and Chaos: With Applications to Physics, Biology, Chemistry, and Engineering. Cambridge MA: Westview / Perseus Books Group, 1994, 498 pp. \{ISBN 0-7382-0453-6 pbk\}

[VaGi02] F. Vahid and T. Givargis, Embedded System Design: A Unified Hardware/Software Introduction. New York, NY: Wiley, 2002, 324 pp.

[Valv00] J.W. Valvano, Embedded Microcomputer Systems: Real-Time Interfacing. Pacific Grove, CA: Brooks/Cole, 2000, 839 pp. \{ISBN 0-534-36642-2\}

[Wall00] Jan Wallaczek (ed.), Self-Organized Biological Dynamics and Nonlinear Control: Towards Understanidng Complexity, Chaos and Emergent Function in Living Systems. Cambridge, UK: Cambridge University Press, 2000, 428 pp. \{ISBN 0521-62436-3 hbk\}

[Wang02a] Yingxu Wang, "On cognitive informatics," in Proc. 1st IEEE Intern. Conf. Cognitive Informatics (Calgary, AB; 19-20 August 2002) ISBN 0-76951724-2, pp. 34-42, 2002.

[Wang02b] Yingxu Wang, "The real-time process algebra (RTPA)," Intern. J. of Annals of Software Engineering, vol. 14, no. 10, pp. 235-274, October 2002.

[Wang06] Yingxu Wang, "Cognitive Informatics Towards the future generation computers that think and feel: Keynote," in Proc. 5th IEEE Intern. Conf. Cognitive Informatics, ICCI06, (Beijing, China; July 17-19, 2006) ISBN 1-4244-0475-4, pp. 3-7, 2006.

[Wang10a] Yingxu Wang, "Cognitive robots: A reference model towards intelligent authentification," 
IEEE Robotics \& Automation Magazine, vol. 17, no. 4, pp. 54-62, Dec 2010.

[Wang10b] Yingxu Wang, "Abstract intelligence and cognitive robots," J. Behavioral Robotics, vol. 1, no. 1, pp. 66-72, 2010.

[WaKZ09] Yingxu Wang, Witold Kinsner, and Du Zhang, "Contemporary cybernetics and its facets of cognitive informatics and computational intelligence," IEEE Trans Systems, Man, and Cybernetics, Part B: Cybernetics, vol. 39, no. 4, pp. 823-833, Aug 2009.

[WaZK10] Yingxu Wang, Du Zhang, and Witold Kinsner (eds.), Advances in Cognitive Informatics and Cognitive Computing. Berlin: Springer Verlag, Vol.
SCI 323, pp. 265-295, 2010, 297 pp. \{ISBN 978-3642-16082-0; eISBN 978-3-642-16083-7\}

[Ward02] Lawrence M. Ward, Dynamical Cognitive Science. Cambridge, MA: MIT Press, 2002, 355 pp. \{ISBN 0-262-23217-0 hbk\}

[Widr10] Bernard Widrow, "Memory and its applications: Keynote," in Proc. 9th IEEE Intern. Conf. Cognitive Informatics, ICCI10, (Beijing, China;, July 7-9, 2010) ISBN 978-1-4244-8040-1, pp. 1-2, 2010.

[Zak03] Stanislaw H. Zak, Systems and Control. Oxford, UK: Oxford University Press, 1003, 704 pp. \{ISBN 019-515011-2\} 